\title{
Formação e participação política do bibliotecário
}

\author{
Geisa Müller de Campos Ribeiro* \\ Suely Henrique Gomes* \\ Hevellin Estrela*
}

Artículo recibido:

17 de abril de 2020

Artículo aceptado:

17 de septiembre de 2020

Artículo de investigación

\section{Resumo}

O objetivo do estudo é identificar o entendimento dos alunos de Biblioteconomia da Universidade Federal de Goiás - Brasil sobre o que são políticas públicas, o conhecimento que possuem sobre participação política e sua relação com a área. $\mathrm{O}$ estudo é de abordagem qualitativa e quanto aos objetivos, exploratório. Utilizou-se como lócus de observação o ensino na Disciplina de Políticas Públicas na área social, cultural e educacional do curso. O instrumento utilizado para a coleta de dados foi aplicação de questionário com perguntas abertas para 25 alunos. Para a compreensão dos dados foi utilizado a técnica

* Universidade Federal de Goiás, Faculdade de Informação e Comunicação, Brasil geisamuller@hotmail.com suelyhenriquegomes@gmail.com hevellinestrela@gmail.com

INVESTIGACIÓN BIBLIOTECOLÓGICA, vol.35, núm. 86, enero/marzo, 2021, México, ISSN: 2448-8321 pp. 123-141 
de análise de conteúdo. Os resultados mostram que os alunos compreendem as políticas públicas como ações e decisões políticas que advém de demandas. O Estado aparece como aquele que resolve os problemas da coletividade por meio de ações. Sobre participação política visualizou-se duas noções de participação: uma voltada ao engajamento nos momentos eleitorais, ao ato político como lócus de participação, e outra mais conceitual voltada a apropriação consciente do sujeito sobre seus atos e a forma como age no/para o mundo. Apesar de compreenderem o que são políticas públicas e participação política, ainda não conseguem pensar a atuação política do campo da Biblioteconomia que é promover sentido informacional à atuação da área.

Palavras-chave: Políticas Públicas; Participação Política do Bibliotecário; Formação Política

Formación y participación política del bibliotecario Geisa Müller de Campos Ribeiro, Suely Henrique Gomes y Hevellin Estrela

\section{RESUMEN}

El objetivo del estudio es identificar la concepción de los alumnos de Biblioteconomía de la Universidad Federal de Goiás - Brasil sobre lo que son políticas públicas, el conocimiento que poseen sobre participación política y su relación con el área. El estudio es un abordaje cualitativo y en cuanto a los objetivos es exploratorio. Se utilizó como lócus de observación la enseñanza en la disciplina de Políticas Públicas en el área social, cultural y educacional del curso. El instrumento aplicado para la recolección de datos fue un cuestionario con preguntas abiertas a 25 alumnos. Para la comprensión de datos fue utilizada la técnica de análisis de contenido. Los resultados muestran que los alumnos comprenden las políticas públicas como acciones y decisiones políticas que provienen de demandas. El Estado aparece como el que resuelve los problemas de la colectividad por medio de acciones. Sobre participación política se observaron dos nociones de participación: una centrada en la participación en los momentos electorales, al acto políticos como lócus de participación y otra más conceptual en torno a 
la apropiación consciente del sujeto sobre sus actos y la forma como actúa en y para el mundo. A pesar de comprender lo que son políticas públicas y participación política, aún no logran pensar la actuación política del campo de Biblioteconomía, que es promover sentido informacional a la actuación del área.

Palabras clave: Políticas Públicas; Participación Política del Bibliotecario; Formación Política

The librarian's education and political participation Geisa Müller de Campos Ribeiro, Suely Henrique Gomes and Hevellin Estrela

\section{Abstract}

The aim of the study was to identify the students' understanding of Librarianship at the Federal University of Goiás - Brazil, about public policies, political participation and its relationship of with the area. The study is qualitative in its approach and exploratory in its objectives. The population of the research consisted of students enrolled in the Public Policy Discipline of the Library Science graduation course of the Federal University of Goiás in the year 2019. The instrument used for data collection was a questionnaire with open questions applied to 25 students. Content analysis technique was used to treat the data. Results show that students understand public policies as actions and political decisions stemming from demands. And the State appears as the one that solves the problems of the Community through actions. Two notions of political participation were identified: one focused on engagement in electoral moments, the political act as the locus of participation; the other one, more conceptual, focused on the subject's conscious appropriation of the individual's acts and the way he/she acts in and for the world. Despite understanding what public policies and political participation are, they still cannot think about the political performance of the field of Library Science, which is, precisely, to promote informational meaning to the performance of the area.

Keywords: Public Policy; Political Participation of the Librarian; Political Formation 


\section{INTRODUÇÃO}

A formação política das sociedades sempre foi uma necessidade urgente A para a manutenção das sociedades democráticas e para a construção de soluções coletivas que dizem respeito a convivência em sociedade e transformação de realidades política, social e econômica. A participação e manutenção do bem comum, no interesse de todos os que vivem em sociedade, é um direito reconhecido da Declaração Universal dos Direitos Humanos - DUDH. Em seu artigo 21, a DUDH reconhece que é dever e direito de todos participarem da elaboração e fiscalização de políticas públicas como forma de equilibrar as demandas de diferentes grupos sociais (Organização das Nações Unidas, 2009).

$\mathrm{O}$ ato político oportuniza a criação de caminhos para negociação, construção de consenso, estabelecimento de diálogo e, principalmente, desenvolvimento da experiência coletiva. Neste âmbito, é importante compreender o Estado como a expressão legítima do poder político, ou seja, uma instância politicamente organizada que, pela legitimação da maioria, administra os múltiplos interesses coletivos (Borba, 2006). As decisões políticas são, portanto, as materializações das ações governamentais denominadas de Políticas Públicas, tão importantes para assegurar a democracia, os direitos de cidadania e os princípios da Constituição. A "forma com que se entende uma política pública está diretamente relacionada com a percepção que se tem do Estado" (Dias, 2011: 319). Por essa razão, a relação entre Estado e políticas públicas é dinâmica.

Pode-se dizer que o campo das políticas públicas é atravessado por inúmeras colaborações disciplinares. Enquanto área de conhecimento acadêmica, está ligada a subárea da Ciência Política e ao longo dos anos seu conceito passou por diferentes ressignificações.

Souza (2003: 12) diz que políticas públicas, segundo alguns autores, é definido como se indica no Quadro 1.

\begin{tabular}{|l|c|}
\hline $\begin{array}{l}\text { Um campo dentro do estudo da política que analisa o governo à luz de grandes } \\
\text { questões públicas. }\end{array}$ & Mead (1995) \\
\hline Um conjunto específico de ações do governo que irão produzir efeitos específicos. & Lynn (1980) \\
\hline $\begin{array}{l}\text { A soma das atividades dos governos, que agem diretamente ou através de delegação, } \\
\text { e que influenciam a vida dos cidadãos. }\end{array}$ & Peters (1986) \\
\hline "O que o governo escolhe fazer ou não fazer". & Dye (1984) \\
\hline
\end{tabular}

Quadro 1. 0 que são políticas públicas

Fonte: adaptado de Souza (2003) 
Para a mesma autora, a definição mais conhecida é a de Laswell (1936, citado por Souza, 2003: 13) que argumenta que "decisões e análises sobre política pública implicam responder às seguintes questões: quem ganha o quê, por quê e que diferença faz" (Souza, 2003: 13).

Todas essas visões apresentam uma noção que posiciona o governo para ação. Em outras palavras, significa dizer que "o processo de formulação de política pública é aquele através do qual os governos traduzem os propósitos em programas e ações, que produzirão resultados ou as mudanças desejadas no mundo real" (Souza, 2003: 13).

Umas das formas de visualizar e interpretar as políticas públicas é por meio de seu ciclo de construção constituído por sete etapas principais. Este ciclo não pode ser entendido como um processo linear, mas com elementos que se conectam e interagem entre si conforme diz Agum, Riscado e Menezes (2015).

Para os mesmos autores, a etapa identificação do problema consiste no reconhecimento e definição do problema público. A identificação pode realizada a partir de partidos políticos, agentes políticos, organizações governamentais e atores sociais. A formulação da agenda traduz os problemas identificados como prioridades. Quando um problema público entra na agenda política passa por um processo de seleção, denominado de formulação de alternativas. Este constitui um momento em que são elaborados métodos, programas, estratégias ou ações para alcançar os objetivos estabelecidos. A fase de decisão consiste no processo de definição do melhor e mais adequado caminho para resolução. O planejamento representa a organização do aparelho administrativo e dos recursos humanos, financeiros, materiais e tecnológicos necessários para implementar uma política. Também corresponde ao monitoramento dessa execução. A avaliação, é o momento em que são verificadas a efetividade das políticas, seus efeitos e a necessidade de sua adequação. Talvez este seja o momento mais crítico de uma política, pois funciona como indicador de comportamento que deve levar à continuação, reestruturação ou mesmo extinção da política.

A partir do exposto, é preciso compreender que para a implementação de uma política há diversificados tensionamentos e embates a respeito de ideias e formas de agir, do que é tecnicamente eficiente e politicamente acessível. Este é o campo de construção e atuação de decisões políticas.

Outro aspecto importante a ser considerado está no conceito de participação política apresentado por Borba (2012). Segundo o autor, este conceito tem tomado diversos desdobramentos. Até então era tratado como fenômeno ligado ao momento eleitoral, mas em função das novas formas de ação política surgem outras modalidades não convencionais manifestada nos padrões comportamentais dos cidadãos. Então, tem-se duas categorias analíticas de 
participação, sendo: participação política convencional, que está ligada a eleição e a estrutura institucional como cerne do processo político, e a participação não convencional, caracteriza pelo engajamento em espaços fora da arena tradicional. Estas duas tipologias tem sido utilizadas para diferenciação entre as diversas formas de participação e a posiciona a um status de busca de coletividade que geram novos espaços de representação, como as mídias sociais, por exemplo.

Muitas decisões políticas e seus desdobramentos sempre impactaram a Biblioteconomia no Brasil, tome-se como exemplo a realidade das bibliotecas públicas que, institucionalmente, são regulamentadas por políticas públicas culturais municipais, estaduais ou federais. Além disso, está área de atuação se depara com a dimensão informacional, que é peça essencial para o desenvolvimento da sociedade e, enquanto política pública, pode ser considerada instrumento fundamental para democratização de seu acesso e ao conhecimento.

Para Carvalho (2016) a construção política da biblioteconomia deve acontecer em permanente diálogo com suas categorias. Esse diálogo é condicional para fortalecimento do tripé Biblioteconomia - Política - Informação a partir dos seguintes vieses: 1) A biblioteconomia atua como disciplina pautada no acesso à informação, seja no fazer profissional e acadêmico, seja no fazer político-institucional; 2) a política como processo de análise, governo, e tomadas de decisão se institui como aspecto de mediação que liga a biblioteconomia à prática informacional; 3) a necessidade de integração política entre setores da área, e 4) política biblioteconômica atrelada ao cotidiano, aproximando o fazer biblioteconômico-informacional da sociedade.

Por essa e outras razões, contemplar a formação política dos graduandos de cursos de Biblioteconomia no Brasil é um grande desafio, principalmente quando se pauta a política enquanto objeto de "formação, de atuação, relacionada a comportamento e competência profissional para que o bibliotecário participe efetivamente da construção da sociedade" (Spudeit, Moraes e Correa, 2016: 27).

Segundo Valentim (2018), não se trata de desenvolver competência político-partidária, mas de desenvolver competência política no sentido de informar para consolidar a democracia; informar para o desenvolvimento social; informar para obter qualidade de vida; informar para diminuir a ignorância em relação aos direitos constituídos por lutas históricas, e informar para o exercício da cidadania plena.

A formação de um profissional político-crítico exige conhecimento interdisciplinar sempre focado nas relações sociais e políticas. Essa efetivação só é possível por meio do processo de educação que possibilita aos cidadãos capacidade de compreender, entender e questionar a política, sendo fundamental 
sua inserção em qualquer área de conhecimento. Silva (2017) considera que "Todo e qualquer campo do conhecimento está inexoravelmente vinculado à formação política, no sentido da concepção técnico-científica (dos múltiplos fazeres da comunidade acadêmica), da prática profissional e da luta político-institucional dos órgãos de classe, tais como Conselho, Associação e/ou Sindicato".

É neste sentido que acredita-se que a biblioteconomia deve se dedicar ao estudo da dinâmica, estruturação e cenário das políticas públicas, principalmente por seu potencial transversal. Silva (2017) identifica três tipos de políticas cruciais de atuação biblioteconômica: políticas públicas de cultura, educação, e informação.

Podemos dizer que a maior área de destaque e discussão no Brasil recai sobre as políticas públicas de informação que são cada vez mais objetos de ações governamentais e de investigação em vários campos de conhecimento (Jardim, Silva e Nharreluga, 2009: 2). Sebastián, Rodríguez e Mateos (2000) discorrem sobre a dimensão política da informação guiada para orientações e diretrizes para consecução do direito à informação e como estratégia para estimular as novas dinâmicas tecnológicas. Portanto, são norteadas por um conjunto de valores políticos que atuam como parâmetros que guiam sua formulação e execução e por isso contempla aspectos administrativos, legais, científicos, tecnológicos, etc.

São nestes pilares que a biblioteconomia brasileira tem sua exponencialidade mais ativa e plena na execução de políticas públicas. Dentre elas podemos destacar: políticas públicas do livro, políticas públicas de leitura, políticas públicas para bibliotecas, políticas públicas de acesso à informação, políticas públicas de acesso à informação científica e tecnológica, políticas públicas de inclusão digital e acessibilidade informacional, entre outras.

Entretanto, um dos grandes entraves está relacionado as carências que tem se observado nos currículos de graduação no Brasil ${ }^{1}$ é a escassez de disciplinas desde os períodos iniciais para discutir e construir conhecimento no âmbito das diversas políticas públicas, principalmente as de informação, voltadas tanto para as práticas de ensino, pesquisa e extensão, como a aplicação profissional.

Essa falta de formação, pode ser frequentemente refletida no desempenho profissional, resultando em um ator que não entende seu papel nos campos social e político, o que inclui, não apenas a capacidade de entender a realidade, mas de agir e interferir nela de maneira concreta.

1 São diversas as pesquisas que comprovam esta carência nos currículos das escolas de biblioteconomia no Brasil, como por exemplo, os estudos de Spudeit, Moraes e Correa (2016), Valentim (2018) e Silva (2017). 
A partir desta perspectiva e da compreensão que as instituições de ensino possuem papel fundamental em contribuir para formação política dos indivíduos, que esta pesquisa tem como objetivo conhecer a opinião dos alunos de Biblioteconomia da Universidade Federal de Goiás, futuros bibliotecários, sobre o que são políticas públicas, o conhecimento que possuem sobre participação política e sua relação com a área.

Acredita-se que a formação política do bibliotecário propicia uma visão ética, política e crítica da profissão comprometida com a construção do projeto de emancipação humana. Além do mais, pensar a "relação entre biblioteconomia e política é promover sentido informacional à atuação da área" (Carvalho, 2016: 61). Nesse sentido, o estudo apresenta resultados parciais da pesquisa obtidos no primeiro trimestre do ano de 2019, ano em que a política brasileira foi marcada por profundas mudanças na administração pública e visa aumentar o debate na área que não é recorrente.

\section{Metodologia}

Segundo Gil (2010) o método científico é um conjunto de procedimentos intelectuais e técnicos adotados para se atingir o conhecimento. Portanto, a presente pesquisa é de abordagem qualitativa e quanto aos objetivos, exploratória. Para os procedimentos adota-se estudo de caso, pois teve como locus de observação o ensino na Disciplina de Políticas Públicas na área social, cultural e educacional do curso de Biblioteconomia da universidade Federal de Goiás.

O instrumento utilizado para a coleta de dados foi um questionário com as seguintes questões abertas: a) o que são políticas públicas; e b) qual o seu entendimento sobre participação política. Também foram realizadas perguntas informais durante a aula sobre a relação da política com a Biblioteconomia. O questionário foi respondido por 25 alunos matriculados na disciplina Políticas Públicas Educacionais, Culturais e Sociais no ano de 2019.

Para o tratamento dos dados foi utilizado a técnica de análise de conteúdo que destaca como etapas essenciais desta metodologia os seguintes passos: categorização, descrição e interpretação. Segundo Moraes (1999: 8) "Essa análise, conduzindo a descrições sistemáticas, qualitativas ou quantitativas, ajuda a reinterpretar as mensagens e a atingir uma compreensão de seus significados num nível que vai além de uma leitura comum”. Portanto, para essa pesquisa a análise esta dirigida à questão "para dizer o quê?". Isso significa que está direcionado para as características das mensagens, seu valor informacional, palavras, argumentos e ideias nela expressos. Para a realização das nuvens de palavras foi utilizado a ferramenta de análise Power B.I. 
Sobre a pergunta A, foram identificadas as seguintes categorias das próprias respostas: políticas públicas como decisões políticas, demandas e ações. Para a pergunta B, identificaram-se as categorias: participação política como "momentos eleitorais" - ato político; e participação política como apropriação consciente do sujeito sobre seus atos políticos.

\section{Apresentação e anÁlise dos resultados}

\section{Uma definição de políticas públicas}

Uma das categorias identificadas nas entrevistas diz respeito às políticas públicas como decisões políticas. Segundo Borba (2006) uma ação governamental é resultado de uma decisão política que se materializa no que se denomina de políticas públicas. Suas definições geram em torno da ação para resolução de problemas e das interações e cooperação entre governos, outras instituições e grupos sociais. Essa compreensão pelos alunos é perceptível ao identificar em algumas respostas palavras como iniciativas, ações, programas, todas voltadas ao contexto de decisão, como se pode observar em alguns comentários: “[...]São o conjunto das decisões políticas e ações políticas, voltadas (teoricamente) ao bem-estar social, [...] tomada de decisões, [...] realização de ações solucionadoras para essas questões apresentadas, [...] Ação, é o poder de se expressar de diversas formas, é a ideia de poder [...]” (Alunos).

O processo de formulação de uma política envolve a identificação dos diversos atores e dos diferentes interesses que permeiam uma determinada questão na agenda pública e, posteriormente, a sua regulamentação como política pública. Ou seja, são as demandas que definem as ações governamentais e as decisões políticas. Muitos alunos compreendem políticas públicas desenvolvidas como demandas sociais apresentadas pela sociedade: "Quando surge uma necessidade da população. [...] problema geralmente fica em evidência quando acorre algo mais grave. [...] para a resolução do problema. [...] desenvolvidas a partir da necessidade de uma sociedade. [...] atender essas demandas. [...] demandas da população" (Alunos).

Ao realizarem estas afirmações, os alunos evocam a função que a sociedade exerce na elaboração das políticas públicas, ou seja, é necessário que exista uma interseção benéfica na constituição de Políticas Públicas com a participação do Estado, Governo e principalmente da sociedade. Muitos também compreendem os tipos de demanda ao mencionarem em suas respostas catástrofes, tragédias. O que também pode estar relacionado a possíveis movimentos, conforme algumas respostas: 
[...] baseado na percepção de falhas em processos já existentes e novas demandas da sociedade, ocasionadas por mudanças culturais, econômicas e até mesmo tragédias. [...] Muitas vezes esses problemas são identificados por crises ou catástrofes. [...] mas que também podem ser definidas extraordinariamente em caso de catástrofes e tragédias, ou em caso de causas defendidas por representantes políticos. (Alunos)

Outra categoria identificada nos depoimentos é o conceito de políticas públicas relacionado às ações políticas. Pode-se dizer que esta noção está voltada a uma definição administrativa do conceito, já que se compreende a implementações das decisões tomadas. Em muitas respostas o Estado aparece como aquele que resolve os problemas da coletividade por meio de ações.

Iniciativas que o Estado adota após análise da situação social dos seus contribuintes. [...] ações políticas que são tomadas pelo estado. [...] é a forma de o Estado materializar o que foi prometido. [...] são programas, planos de política, realizados pelo Estado [...] O Estado tem participação ativa nessas demandas [...] o Estado tem a função de elaborar planos de ações para suprir as políticas públicas e tomar as devidas decisões que mais se adequada a determinado problema, [...] tem o poder de receber as demandas da população e criar projetos de ações para tentar satisfazê-las. [...] garantir ao homem um modo de convívio com seus iguais de modo que atenda aos interesses de ambos [...] buscar as necessidades da população, para assim criar políticas públicas que auxiliem a vida do cidadão, nas áreas da saúde, educação, saneamento, transporte, meio ambiente, moradia e qualidade de vida, segurança, entre outras áreas afins [...]. (Alunos)

É importante salientar, conforme Dias (2011) que as Políticas públicas não devem ser entendidas apenas como o que o Estado faz, enquanto dimensão mais percebida, mas também como aquilo que ele deixa de fazer: poderíamos dizer que é o Estado em movimento.

A nuvem de palavras na Figura 1, reforça a categoria identificada: Políticas públicas como decisões políticas, demandas e ações. Observa-se que as palavras com maiores destaques são: demandas, programas, poder, população, decisões, sociedade, Estado e a palavra ações que a partir da contagem evocações, aparece 15 vezes.

\section{Participaçáo política}

Levantar como os alunos definem participação política possibilitou identificar uma série de modalidades de participação e de comportamentos participativos interessantes de serem analisados. Inicialmente, podemos definir política como o exercício do homem na organização do bem comum para 
que todos desfrutem dos benefícios que é construído coletivamente (Borba, 2006). Logo, a participação política designa a construção deste coletivo sempre preservando o bem comum. É muito comum as pessoas sempre relacionarem participação política ao conjunto de atividades relacionadas aos momentos eleitorais. Nas respostas dos alunos, esta foi a primeira categoria identificada. Observa-se que há nesse primeiro momento uma noção mais empírica de engajamento, isso é, como um ato participativo.

Ato de votar e posteriormente fiscalizar os candidatos eleitos. [...] Após as eleições se preocupar e cobrar as promessas feitas pelo candidato. [...] as eleições que movimentam pessoas e ideias diferentes. [...] como votar, se candidatar a algum cargo eletivo, apoiar um candidato. [...] contribuir financeiramente com algum partido ou candidato, se juntar a um partido, apoiar publicamente seu candidato, participar direta ou indiretamente de alguma decisão política em relação a sociedade. [...] participar das eleições, escolhendo racionalmente um candidato. [...] se reunir e realizar manifestações a respeito de algum projeto lei que está sendo votado. (Alunos)

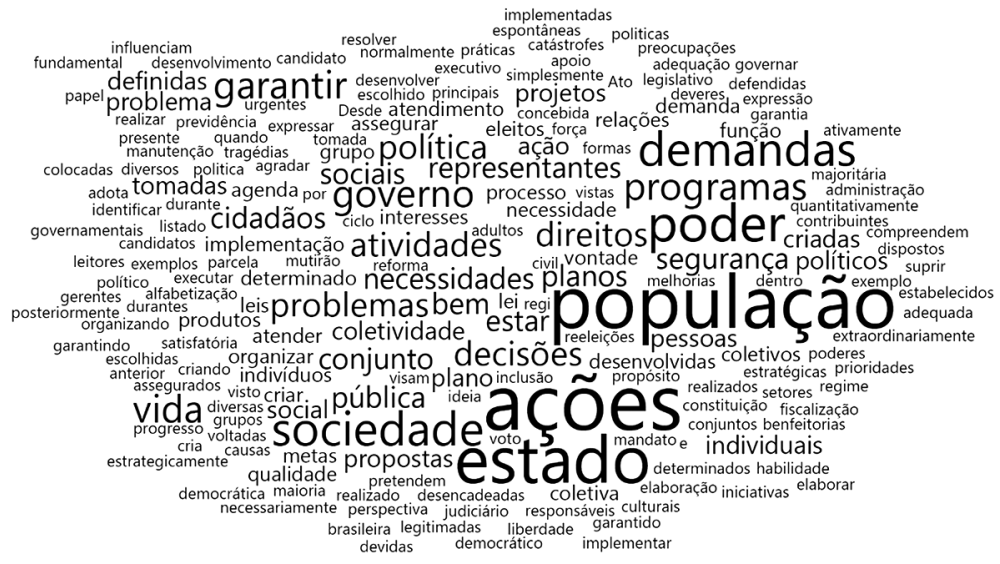

Figura 1.0 que são políticas públicas?

Fonte: elaborado pelas autoras (2019)

Também é importante considerar que sobre esta questão, as repostas apresentam a participação política relacionada aos momentos eleitorais como lócus de participação. É preciso considerar que há várias formas de ações coletivas. A segunda categoria identificada pode ser denominada de apropriação consciente do sujeito sobre seus atos e a forma como age no/para o mundo, em outras palavras significaria dizer "o quão informados, conscientes e interessados são sobre”, conforme algumas respostas obtidas: 
É tomar partido. Não no sentido de ter filiação política a partidos, ou movimentos, mas ter uma opinião. [...] estamos fazendo e participando da política em todos os momentos. [...] o ato de conversar sobre a política e se interessar por coisas políticas. [...] Não precisa estar afiliada a um pensamento ou movimento específico da política. [...] se preocupar e cobrar as promessas feitas pelo candidato. [...] possibilidade de influenciar de forma efetiva as políticas locais, regionais, nacionais e internacionais. [...] fiscalizar os candidatos eleitos, talvez até na conscientização de outras pessoas, indagando, provocando o pensamento. [...] cobrar as decisões das pessoas que estão no governo representando a sociedade por meio de reuniões. (Alunos)

A nuvem de palavras na Figura 2 reforça, por meio dos termos mais evocados, as categorias identificadas na análise de conteúdo: participação política como "momentos eleitorais" - ato político; e participação política como apropriação consciente do sujeito sobre seus atos políticos.

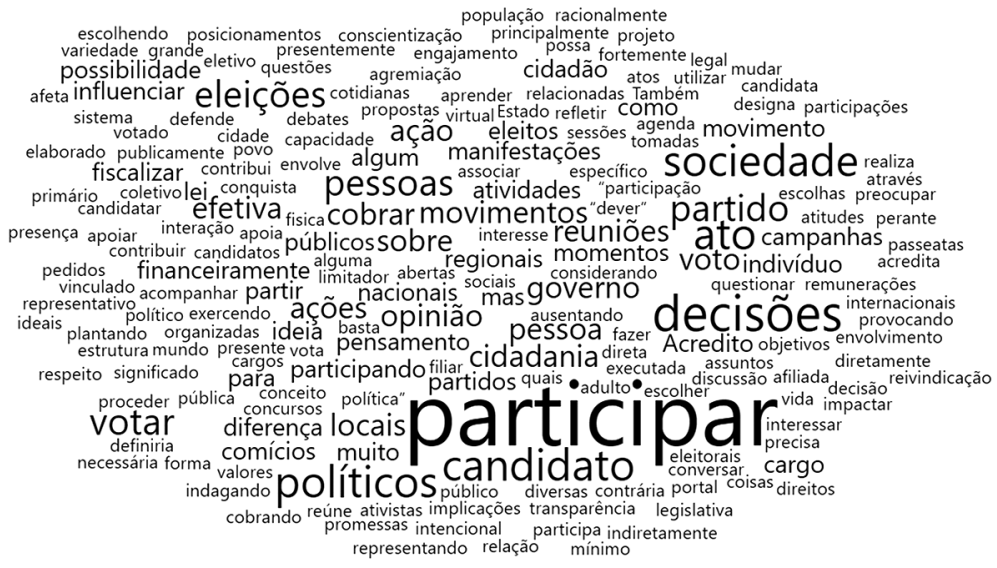

Figura 2. 0 que é participação política?

Fonte: elaborado pelas autoras (2019)

\section{Relaçáo com a Biblioteconomia}

A classificação da Biblioteconomia na área de Ciências Sociais Aplicadas e as diretrizes para a promoção de uma formação humanista-social na atuação do profissional impõem uma compreensão mais profunda do campo político e da dinâmica de construção de políticas públicas. Na tentativa de observar se os alunos conseguem compreender esta dimensão, foram realizadas perguntas informais para a turma. (como vocês relacionam a biblioteconomia com políticas públicas?). Unanimemente, durante todas as aulas em que eram 
realizadas essas abordagens ou discussões para tensionar o debate, nenhum aluno conseguia responder.

O que se evidencia é que existe o entendimento sobre políticas públicas e sua participação na esfera civil, relacionadas a sociedade política conforme evidenciado nos outros objetivos da pesquisa, mas os alunos ainda não conseguem pensar a atuação política do campo da Biblioteconomia e suas relações.

Segundo Valentim (2018), as políticas públicas que contemplem informação se constituem como alicerce para que a sociedade possa exercer seus direitos constitucionais, já que a informação é matéria prima para a construção do conhecimento e é por meio dela que o cidadão identifica, seleciona, compreende, se apropria e usa. Por isso, assessorar e intervir em sua formulação se torna uma competência profissional essencial para o profissional da informação atuar. Além disso, possui a responsabilidade sobre a manutenção ou modificação de uma dada realidade informacional.

No âmbito da formação universitária o discente deve receber conteúdos programáticos que desenvolvam essa competência profissional essencial, cuja finalidade é possibilitar a atuação plena em uma dada realidade social. Portanto, é necessário que os currículos contemplem competências sociais e políticas que proporcionem ao discente conhecimento capaz de alterar uma dada realidade e, assim, possa de fato contribuir para que o cidadão conheça seus direitos básicos e possa agir em benefício próprio e da comunidade na qual está inserido.

Uma pesquisa realizada por Spudeit, Moraes e Correa (2016) onde o objetivo é investigar como ocorre a formação política nos cursos de graduação em Biblioteconomia no Brasil a partir de uma abordagem descritiva dos currículos dos cursos, apresenta que em grande parte os cursos possuem disciplinas que utilizam o termo 'política' na ementa / ou em seu conteúdo programático. Entretanto, estas disciplinas relacionam-se aos processos técnicos e gerenciais do fazer profissional tais como: política de preservação, política de seleção, política de indexação, entre outros. Não há menção nas ementas e conteúdos programáticos das disciplinas sobre atuação política profissional, embora estejam presentes o desenvolvimento de competências políticas no perfil. Isso evidencia a necessidade de a formação em biblioteconomia superar o modelo técnico e compartimentado, de modo a atender as atuais necessidades sociais.

É também possível observar a existência de disciplinas voltadas a formação ética, sociológica ou filosófica do profissional, mas as ementas não mencionam uma discussão sobre a formação política (Spudeit, Moraes e Correa, 2016:37). 
Essa constatação das autoras também é possível visualizar na Universidade Federal de Goiás. A partir da observação da grade curricular do curso de Biblioteconomia $(2016)^{2}$, no eixo de fundamentos ${ }^{3}$, verifica-se somente uma disciplina que trata especificamente sobre políticas, sendo: Políticas Públicas na área social, cultural e educacional. Em nenhuma outra disciplina é possível encontrar quaisquer abordagens e aspectos propriamente relacionados à formação política do bibliotecário, conforme Quadro 2.

\begin{tabular}{|c|c|}
\hline Disciplinas & Ementa do Eixo de Fundamentos \\
\hline Sociedade, Cultura e Educação & $\begin{array}{l}\text { Análise teórica da constituição da sociedade, saber e educação. } \\
\text { Historicidade e mediação na constituição da sociedade, racionalidade e } \\
\text { projetos educacionais. Processos de socialização: a família, a cultura, } \\
\text { os meios de comunicação de massa, a indústria cultural, a religião, a } \\
\text { arte e a escola. }\end{array}$ \\
\hline $\begin{array}{l}\text { História dos Registros do } \\
\text { Conhecimento }\end{array}$ & $\begin{array}{l}\text { História dos registros do conhecimento: livro, leitura e bibliotecas. As } \\
\text { bibliotecas antigas, medievais e contemporâneas. A escrita, a imprensa } \\
\text { e seus efeitos. Formação e história dos registros do conhecimento no } \\
\text { Brasil. Produção atual dos registros do conhecimento. }\end{array}$ \\
\hline $\begin{array}{c}\text { Fundamentos } \\
\text { da Biblioteconomia }\end{array}$ & $\begin{array}{l}\text { Fundamentos teóricos, históricos e aplicação da Biblioteconomia. } \\
\text { Evolução e os campos da Biblioteconomia: princípios, objetivos e } \\
\text { terminologias profissionais. Função social, educativa e cultural das } \\
\text { bibliotecas e outras unidades de informação. A natureza constitutiva das } \\
\text { bibliotecas e unidades de informação. Relações etnoraciais; história e } \\
\text { cultura afro-brasileira e indígena. }\end{array}$ \\
\hline $\begin{array}{l}\text { Políticas públicas na área social, } \\
\text { cultural e educacional }\end{array}$ & $\begin{array}{l}\text { Políticas públicas: aspectos históricos, conceituais e teóricos. } 0 \\
\text { papel do Estado e atuação da sociedade civil nas políticas públicas. } \\
\text { Plano Nacional de Educação (PNE) e Plano Nacional de Cultura (PNC); } \\
\text { Políticas Públicas de informação em Educação e Cultura: Legislação e } \\
\text { Programas. }\end{array}$ \\
\hline Fundamentos da Educação & $\begin{array}{l}\text { Os processos educacionais a partir de seus fundamentos teóricos e } \\
\text { metodológicos e a prática pedagógica. A constituição dos processos } \\
\text { educacionais no âmbito da sociedade e da cultura, partindo da contri- } \\
\text { buição de diferentes áreas do conhecimento. Estrutura e funcionamento } \\
\text { do ensino. } 0 \text { Projeto Político Pedagógico (PPP) (Universidade Federal de } \\
\text { Goiás, 2016): a biblioteca, o currículo e a avaliação educacional. }\end{array}$ \\
\hline
\end{tabular}

2 Não é objetivo desta pesquisa realizar uma análise do currículo do curso, mas somente apresenta-lo para fomentar a discussão.

3 O Projeto Político Pedagógico do curso de Biblioteconomia (Universidade Federal de Goiás, 2016) está apoiado em cinco eixos, sendo: administrativo, técnico, tecnológico, fundamentos, e eixo metodológico. O eixo de fundamentos trata de: Fundamentos teóricos e epistemológicos do campo da Educação, Filosofia, Sociologia, Literatura, História, Linguística, Psicologia, Comunicação, Tecnologia e Biblioteconomia. A crítica da produção teórica da Biblioteconomia em articulação com as áreas Social, Cultural e Educacional, seus fundamentos e implicações na prática profissional. Acredita-se que este eixo é o mais representativo do quadro social e cultural que as políticas públicas permeiam. As demais apresentam aspectos mais técnicos da área. 


\begin{tabular}{|c|c|}
\hline Psicologia, educação e cultura & $\begin{array}{l}\text { A psicologia e suas contribuições para a compreensão dos processos } \\
\text { educativos. } 0 \text { desenvolvimento humano e as principais correntes } \\
\text { teóricas contemporâneas. Processos de aprendizagem. }\end{array}$ \\
\hline Leitura e Sociedade & $\begin{array}{l}\text { Leitura e leitores: aspectos teóricos e conceituais. Leitura e sociedade: } \\
\text { análise e perspectivas. Leitura: mediação e mediadores. A leitura na } \\
\text { família, na escola, e nas bibliotecas. Programas e políticas de promoção } \\
\text { e acesso à leitura. Os diferentes modos, fontes, formatos e suportes de } \\
\text { produção da leitura. }\end{array}$ \\
\hline $\begin{array}{c}\text { Produção cultural para crianças } \\
\text { e jovens }\end{array}$ & $\begin{array}{l}\text { Noção de criança e jovem na sociedade contemporânea. Maneira como } \\
\text { a sociedade concebe e cristaliza o modo de ser da criança e do jovem. } \\
\text { Os mecanismos da cultura como mediadores na interação social. } \\
\text { A criança na produção cultural a ela destinada. Produção cultural: } \\
\text { circunstâncias de produção e consumo. Análise dos bens culturais: } \\
\text { audiovisual; HQ; tecnologias; livros literários, didáticos e outros. }\end{array}$ \\
\hline Teoria da Ação Cultural & $\begin{array}{l}\text { Sociedade e cultura no Brasil. As contribuições históricas da cultu- } \\
\text { ra-afro-brasileira e indígena. A diversidade na cultura brasileira. } 0 \\
\text { Sistema de produção cultural. Biblioteca e política cultural. A Biblioteca } \\
\text { no circuito cultural do Estado. Centros de cultura. Biblioteca e ação } \\
\text { cultural. Preservação e geração de bens culturais. }\end{array}$ \\
\hline $\begin{array}{l}\text { Tópicos Contemporâneos em In- } \\
\text { formação social, cultural e edu- } \\
\text { cacional: cultura afro-brasileira: } \\
\text { mediações da informação étnico } \\
\text { racial; o cultura informacional e } \\
\text { meio ambiente o biblioteca no } \\
\text { contexto escolar; o biblioteca no } \\
\text { contexto sócio-cultural }\end{array}$ & Disciplinas optativas e não apresentam ementa. \\
\hline
\end{tabular}

Quadro 2. Ementa do Eixo de Fundamentos do curso de Biblioteconomia da UFG Fonte: Universidade Federal de Goiás (2016)

Observa-se que o eixo de fundamentos apresenta noções importantes que servem como pano de fundo para o âmbito das políticas públicas, como formação ética, sociológica ou filosófica do profissional, mas não visualizamos tópicos nas ementas destas disciplinas como democracia, instituições políticas, relações de poder, cidadania, movimentos sociais, conscientização política e liderança, reformas políticas, partidos políticos, divisão dos poderes, entre outros assuntos relacionados.

Talvez seja por causa desta fragilidade que os alunos não conseguem compreender e refletir sobre a atuação política do campo da Biblioteconomia, o que exigiria um estudo mais profundo sobre o tema. Outras problemáticas podem estar relacionadas a falta de metodologias pedagógicas no ensino na graduação, falta de abordagens interdisciplinares entre as disciplinas ou a inserção da única disciplina observada somente no sétimo período do curso. Isso, considerado do ponto de vista do estudo é um pouco tardio, diante da quantidade de temas que precisam ser abordados. 
Silva (2017) propõe algumas possibilidades de formação política na Biblioteconomia, como:

- Inserção de disciplinas obrigatórias e/ou optativas no âmbito da graduação sobre perspectivas políticas e éticas na Biblioteconomia;

- Articulação dos Centros/Diretórios Acadêmicos na proposição de fóruns e cursos de formação política aplicada à Biblioteconomia.;

- Atividades de extensão como cursos, eventos e prestação de serviços sobre a atuação política da Biblioteconomia;

- Desenvolvimento de projetos de pesquisa sobre perspectivas de atuação no campo da Biblioteconomia, Arquivologia, Museologia, Ciência da Informação e afins;

- Atuação da Associação na promoção da educação continuada em formação política;

- Atuação do Conselho de Biblioteconomia no processo de regulação da atuação político-institucional da área.

Acredita-se que muitas lacunas poderiam ser sanadas por meio de projetos de pesquisa e extensão ou até mesmo com parcerias dos órgãos de classe, como evidenciado. Outro aspecto importante é a necessidade de incentivar os alunos a procurarem por outros aperfeiçoamentos já que as mudanças na Biblioteconomia no Brasil têm exigido novas configurações e demandas que muitas disciplinas não conseguem alcançar.

Sabemos das múltiplas dificuldades que os cursos de Biblioteconomia possuem no Brasil para introduzir temas políticos no currículo escolar. Segundo Spudeit, Moraes e Correa (2016: 41) "a proposta de repensar os conteúdos das disciplinas formativas nos cursos de Biblioteconomia brasileiros na direção do debate sobre a atuação política do profissional vai ao encontro não apenas do anseio da classe bibliotecária, mas também de uma demanda real da sociedade contemporânea". Por essa razão é necessário trazer essa discussão à tona, já que pensar a relação entre biblioteconomia e política é promover sentido informacional à atuação da área e na graduação que se alicerça a práxis do profissional que irá atuar.

\section{ConsideraÇões Finais}

Segundo Spudeit, Moraes e Correa (2016: 24) "A necessidade de os cidadãos participarem da vida em sociedade é condição para discutir fatos e conceitos 
da realidade social e política". Portanto, pode-se dizer que a política é uma referência permanente em nosso cotidiano na medida em que se desenvolve como vida em sociedade. Já dizia Maar (2006) que a própria atividade política também significa o exercício de uma atividade transformadora da consciência, das suas relações com o mundo e seu exercício na esfera pública.

Buscou-se na pesquisa compreender a opinião dos alunos do curso de Biblioteconomia sobre o que são políticas públicas, qual conhecimento possuem sobre participação política e sua relação com a área.

Sobre políticas públicas, foi possível observar nas análises das respostas dos alunos três categorias importantes relacionadas ao conceito, como: decisões políticas, demandas e ações. Verifica-se que os alunos conseguem entender que políticas públicas são ações e decisões políticas que advém de demandas. As demandas se apresentam enquanto interesses do Estado e a necessidade de participação da sociedade nas decisões. O Estado aparece como aquele que resolve os problemas da coletividade por meio de ações, ou seja, as políticas públicas se apresentam como o Estado em movimento.

Enquanto futuros bibliotecários, esse entendimento é importante pois suas ações serão orientadas à sua participação crítica na sociedade.

Sobre participação política, visualizou-se duas noções de participação: uma mais empírica, voltada ao engajamento nos momentos eleitorais, ao ato político como locus de participação, e outra mais conceitual voltada a apropriação consciente do sujeito sobre seus atos e a forma como age no/para o mundo. Em outras palavras significaria dizer "o quão informados são sobre". As duas formas estão relacionadas.

Para todo ato político de participação é necessário consciência de atuação. Gomes (2005) argumenta que sobre a participação política podem existir dois extremos, uma bastaria que a população votasse e a outra que fosse politicamente bem informada. Mas o entendimento não se encerra somente sobre estas considerações.

De forma geral, compreende-se que os alunos possuem entendimento sobre políticas públicas e participação política. O grande questionamento é se levarão esse entendimento para atuação na área ao se formarem, já que não vislumbram as competências políticas da Biblioteconomia e seu papel junto à sociedade, não só no que tange o acesso à informação, mas de sua responsabilidade sobre a manutenção ou modificação de uma dada realidade informacional e seus aspectos críticos. Aqui cabe a atuação do professor e dos projetos pedagógicos dos cursos que devem interagir entre diversificadas áreas e proporcionar as abordagens necessárias para atingir as competências essenciais para a formação do profissional. 


\section{REFERÊNCIAS}

Agum, Ricardo, Priscila Riscado e Monique Menezes. 2015. "Políticas Públicas: Conceitos e Análise em Revisão”. Revista Agenda Política 2 (3): 12-42. http://www.agendapolitica.ufscar.br/index.php/agendapolitica/article/view/67

Arendt, Hannah. 2002. O que épolítica. 3a. ed. Rio de Janeiro: Bertrand Brasil.

Bobbio, Norberto. 1987. Estado, governo e sociedade: para uma teoria geral da política. 4a. ed. Rio de Janeiro: Paz e Terra.

Borba, Julian. 2006. Ciência política. Florianópolis: SEaD/UFSC.

Borba, Julian. 2012. "Participação política: uma revisão de modelos de classificação". Sociedade e Estado 2 (27): 263-288. https://doi.org/10.1590/S0102-69922012000200004

Carvalho, Jonathas. 2016. Tópicos em biblioteconomia e ciência da informação: epistemologia, política e educação. Rio de Janeiro: Agência Biblioo.

Dias, Rafael de Brito. 2011. “O que é a política científica e tecnológica”. Sociologias 28 (13): 316-344. https://doi.org/10.1590/S1517-45222011000300011

Gil, Antônio Carlos. 2010. Como elaborar projetos de pesquisa. 5a. ed. São Paulo: Atlas.

Gomes, Wilson. 2005. "Internet e participação política em sociedades democráticas”. Revista Famecos 27: 58-78.

http://revistaseletronicas.pucrs.br/ojs/index.php/revistafamecos/article/ view/3323/2581

Jardim, José Maria, Sérgio Conde de Albite Silva e Rafael Simone Nharreluga. 2009. "Análise de políticas públicas: uma abordagem em direção às políticas públicas de informação”. Perspectivas em Ciência da Informação 14 (1):2-22.

http://portaldeperiodicos.eci.ufmg.br/index.php/pci/article/view/743

Maar, Wolfgang Leo. 2006. O que épolítica?. São Paulo: Brasiliense.

Moraes, Roque. 1999. "Análise de conteúdo". Revista Educação 37 (22): 7-32. http://cliente.argo.com.br/ mgos/analise_de_conteudo_moraes.html

Organização das Nações Unidas. 2009. Declaração Universal dos Direitos Humanos, Centro de Informação das Nações Unidas para o Brasil (UNIC) 5. https://nacoesunidas.org/wp-content/uploads/2018/10/DUDH.pdf

Sebastián, Mercedes Caridad, Eva Méndez Rodríguez e David Rodríguez Mateos. 2000. "La necesidad de políticas de información ante la nueva sociedad globalizada”. Ciência da Informação 29(2): 22-36.

https://www.scielo.br/pdf/ci/v29n2/a04v29n2.pdf

Silva, Jonathas Luiz Carvalho. 2017. "Como atuar com políticas públicas na biblioteconomia?". INFOhome.

https://www.ofaj.com.br/colunas_conteudo.php?cod=1074

Souza, Celina. 2003. "Políticas públicas: questões temáticas e de pesquisa". Caderno CRH 39: 11-24.

https://portalseer.ufba.br/index.php/crh/article/view/18743

Spudeit, Daniela, Marielle Barros de Moraes e Elisa Delfini Correa. 2016. "Formação política do bibliotecário no Brasil". REBECIN 1 (3): 24-46. https://www.brapci.inf.br/index.php/res/v/71686

Universidade Federal de Goiás. 2016. Projeto Político Pedagógico: Biblioteconomia. Goiânia. https://files.cercomp.ufg.br/weby/up/75/o/projeto_pedag\%C3\%B3gico_ DEZEMBRO_01.pdf 
Valentim, Marta Lígia Pomim. 2018. "A importância da atuação política do profissional da informação", em Formação e atuação política na Biblioteconomia, organizado por Daniela Fernanda Assis de Oliveira Spudeit, Danielle Borges Pereira, Irajayna de Sousa Lage Lobão, Jéssica Glienke David, 55-75. São Paulo: ABECIN Editora.

Para citar este texto:

Ribeiro, Geisa Müller de Campos, Suely Henrique Gomes e Hevellin Estrela. 2021. "Formação e participação política do bibliotecário". Investigación Bibliotecológica: archivonomía, bibliotecología e información 35 (86): 123-141.

http://dx.doi.org/10.22201/iibi.24488321xe.2021.86.58261 